\title{
Long-term crustal movement caused by the Chiuchiungkeng Fault in southwestern Taiwan: Constraints from luminescence dating
}

\author{
Y.W. Chen ${ }^{\mathrm{a}, \mathrm{b}}$, Y.G. Chen ${ }^{\mathrm{a}, *}$, A.S. Murray ${ }^{\mathrm{b}}$, T. Watanuki ${ }^{\mathrm{a}}$, W.S. Chen ${ }^{\mathrm{a}}$, C.C.B. Yang ${ }^{\mathrm{a}}$, \\ T.K. Liu ${ }^{\mathrm{a}}$, C.W. Lin ${ }^{\mathrm{c}}$ \\ ${ }^{a}$ Department of Geosciences, National Taiwan University, No. 1, Sec. 4, Roosevelt Road, Taipei 106, Taiwan, Republic of China \\ ${ }^{\mathrm{b}}$ The Nordic Laboratory for Luminescence Dating, Department of Earth Sciences, University of Aarhus, Risø DTU, DK-4000 Roskilde, Denmark \\ ${ }^{\mathrm{c} C e n t r a l ~ G e o l o g i c a l}$ Survey, MOEA, No. 2, Lane 109, Hua-Hsin Street, Chung-Ho, Taipei 235, Taiwan, Republic of China
}

Available online 13 August 2008

\begin{abstract}
To investigate the long-term crustal movement of the Chiuchiungkeng Fault (CCKF), a proposed active fault located in the southwestern coastal plain of Taiwan, two boreholes and dissected alluvial fans were selected for determination of depositional ages using luminescence. The standard single-aliquot regenerative-dose (SAR) protocol was applied to large aliquots of 90-150 $\mu \mathrm{m}$ quartz, with dose rates based mainly on high-resolution gamma spectrometry. The laboratory growth curves show a relatively large saturation value, which should allow reliable ages to be determined back to $\sim 150 \mathrm{ka}$. To test whether a significant sensitivity change occurred during natural measurement, the single-aliquot regeneration and added dose (SARA) method was also used to estimate equivalent dose; this showed that a sensitivity change of $\sim 4 \%$ may be introduced during the routine SAR procedure. The age results, unaffected by significant sensitivity change, all lie within 60-105 ka, and an $80 \mathrm{ka}$ synchronous surface is used to evaluate the long-term fault behaviour. Based on the offset across the hanging wall and footwall, a long-term fault slip rate of $\sim 1.5 \mathrm{~m} \mathrm{ka}^{-1}$ is estimated for the near-surface CCKF. From the anomalously steep slope of an $80 \mathrm{ka}$ abandoned fan surface observed in the hanging wall, a long-term tilt rate of $\sim 42 \mathrm{~m} \mathrm{~km}^{-1}$ can be also derived based on the assumption that the initial slope is given by the modern river bed. Finally, it is deduced that the slip rate of the CCKF along its deeper part must be greater than $\sim 1.5 \mathrm{~m} \mathrm{ka}^{-1}$ since the apparent rate is reduced by folding of the hanging wall.

(C) 2008 Elsevier Ltd and INQUA. All rights reserved.
\end{abstract}

\section{Introduction}

The Philippine Sea plate and the Eurasian plate have been colliding since the late Miocene, resulting in the emergence of Taiwan. The island is composed of five major topographical and lithostratigraphic subdivisions: the Coastal Plain (alluvial cover), the Western Foothills (clastic sediments), the Central Range (argillite-slate series and metamorphic complex), the Longitudinal Valley (major suture), and the Coastal Range (volcaniclastic and turbiditic sediments; Ho, 1986; Teng, 1990). This oblique arc-continent collision has resulted in the progressive migration of active deformation and foreland basin development southwards and westwards (Suppe and Namson, 1979). Chapple (1978) showed that an actively

\footnotetext{
${ }^{*}$ Corresponding author. Tel.: + 886223697648 ; fax: +886223644625

E-mail address: ygchen@ntu.edu.tw (Y.G. Chen).
}

deforming fold-and-thrust belt is mechanically analogous to a wedge of soil and sand in front of a moving bulldozer. The Coastal Plain and Western Foothills are currently regarded as the active foreland basin and the tip of the critical taper of the fold-and-thrust belt. To the immediate east of the foreland basin a series of imbricated thrust faults has been clearly defined as the frontal thrust wedge of the entire Western Foothills eastwards (Angelier, 1986; Deffontaines et al., 1997; Lu et al., 1998; Mouthereau et al., 2001).

In the national project "Earthquake Geologic Investigation and Data Bank Compilation on Active Faults in Taiwan", the basic survey involved locating faults, determining their characteristics, and analysing their tectonic behaviour (Chen et al., 2003a). Based on seismic interpretation, biostratigraphic correlation, and sedimentary facies analysis (Chi et al., 1998), the continental margin of the Eurasian plate appears to have been extended in the 
early Tertiary by the development of many normal faults. Seismic profiles in the coastal plain area of western Taiwan clearly show that several pre-existing normal faults have been reactivated by subsequent low-angle thrust faults or even turned to reverse faults after the orogeny (Yang et al., 2006). Unfortunately, because of a lack of age control, recent fault activities are largely unknown.

This paper focuses on the Chiuchiungkeng Fault (CCKF), the frontal fault in a series of imbricating thrust faults that were incorporated into the westernmost thrust wedge of the Western Foothills in the late Pleistocene. Tectonic activity in southwestern Taiwan is of concern because this is the main agricultural supply region for the whole island and supports a large population. The CCKF is thought to have the greatest probability of reactivation in this area, and it is highly desirable from a geological, geo-technical, and sociological perspective to know more about the history and present activity of this fault. This was explicitly described in kinematically restored cross-sections (Hung et al., 1999) but the fault could not then be defined as active without further geomorphological and geochronological surveys. The sedimentary rocks in the Western Foothills appear to be beyond the radiocarbon age range, and so there is no chronological basis for interpreting tectonic behaviour in this region. In this study, several samples of woody material were found in the river terrace gravels (Fig. 1; Hsu, 2003), but these were all found to be too old for radiocarbon dating. The various depositional processes resulting from high rainfall and considerable stream power complicate the interpretation of the in-situ
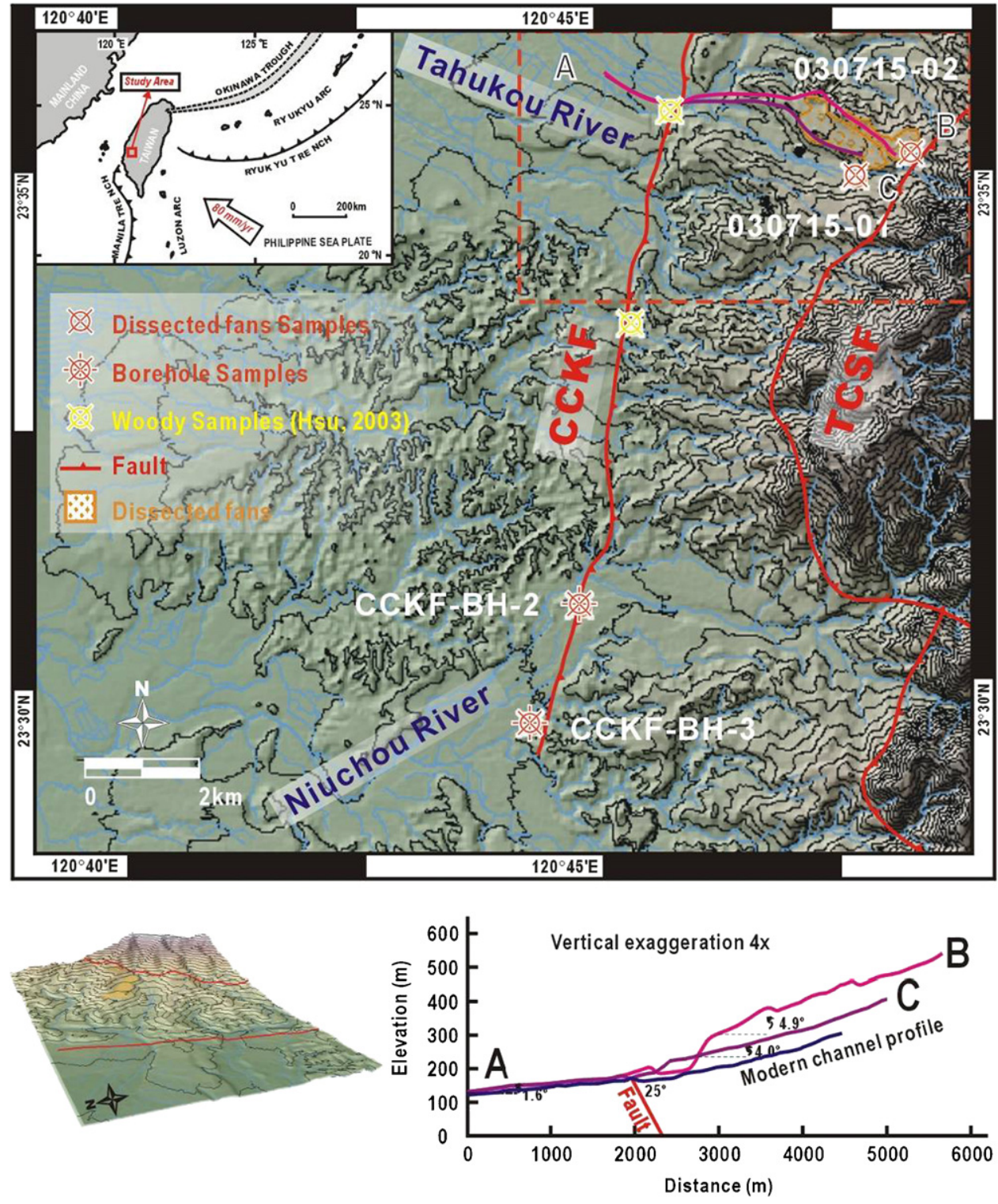

Fig. 1. The sampling site and close-up of the site relief map. The regional tectonic environment is shown in the inset. The dark red dash square shows the locality of the 3D view map at the Tahukou River. The topographic profiles of the cross-sections AB and AC are shown on the map, and the difference between the slopes of the modern channel and dissected alluvial fans shows that tectonic activity on the CCKF has resulted in tilting to give rise to the older dissected fans. 
carbon-containing material because of the likelihood of reworking. Furthermore the dilution by huge amounts of sediment makes studies of pollen, foraminifera, and micro-fossils very difficult. Given previous successful applications of luminescence dating in southwestern Taiwan (Chen et al., 2003b), the same approach was applied to sand-sized quartz extracted from two dissected fan deposits and two borehole deposits; it was expected that these would help determine whether the fault is still active. The depositional ages of two dissected fans are compared with time-equivalent layers in the borehole section, and 18 optical ages from borehole samples are used to compute accumulation rates. The sheared fault zone has been previously identified in the borehole sections (Liu et al., 2003), but the sequence correlation is difficult to achieve owing to frontal deformation on the hanging wall. It was expected that the combination of chronology and the geometry of the old deformed dissected fan surface would allow a better understanding of the faulting history.

\section{Sampling sites and experimental treatment}

\subsection{Geomorphological features}

The shaded relief topographic map (Fig. 1) was derived from the digital elevation model (DTM) of Taiwan on a grid of $40 \mathrm{~m}$, and a $\mathrm{N} 10^{\circ} \mathrm{E}$ lineament parallel to the contours can be identified. Between the CCKF and Tachienshan Fault (TCSF), the distributions of long, narrow terraces parallel to the river indicate this area has been tilted. Based on the number of terraces and the gradient difference, the vertical displacement rate of the northern CCKF segment is thought to be higher than that of the southern segment; this is consistent with the results of seismic reflection (Shih et al., 2002; Wang et al., 2005). It is clear that fault movement has led to river capture and has deflected the river flow parallel to the lineament identified above.

\subsection{Depositional environment and stratigraphy}

In the study area (Fig. 1), the evolving modern river bed and two dissected fans of obviously different ages are used to describe the gradient differences. The older dissected fan (profile AC) appears to have tilted by up to $\sim 2.4^{\circ}$ compared to the modern channel, indicating the effects of the CCKF movement. The 3D view of the geomorphology map at the Tahukou River indicates two steps of river terraces along the modern channel (Fig. 1). Two optically stimulated luminescence (OSL) samples were collected from the sandy layers within fluvial gravel layers from the above two terraces by horizontally pushing opaque plastic tubes into sandy layers. The sampling positions were at depths of $1-2 \mathrm{~m}$ from the terrace surface.

Three wells were drilled along the CCKF in this area to confirm the existence of a fault zone, but only the two southernmost were investigated. The one situated in the middle of the CCKF was avoided because of the possibility of interference from the Hsiaomei anticline and Meishan Fault nearby. Samples for OSL were collected from the two boreholes, and the stratigraphic descriptions and sampling locations are given in Fig. 2. In the CCKF-BH-2 section (Fig. 2a), the fault was identified at $\sim 17 \mathrm{~m}$, where grey-blue fine sand with intercalated mud has been thrust upon fluvial gravel. This is consistent with the field observation in the northern section of the CCKF, which shows that the river terrace gravel (late Pleistocene) is overlain by a thrust silty sand layer (Plio-Pleistocene; Chen et al., 2003a). However, the different lithology of the silty sand and gravel is the only feature in the borehole that suggests the presence of the fault. Liu et al. (2003) were unable to identify shearing associated with the fault zone in the CCKF-BH-3 borehole. OSL ages are needed to establish a time framework and to interpret the behaviour of the CCKF.

Silt to fine-sand layers were chosen for OSL sampling. Unfortunately, the original coring strategy was not planned with OSL dating in mind, and split cores had been archived and dried before this study. As a result, OSL samples were taken only from apparently intact sections, and every attempt was made to ensure that sufficient material was removed from surfaces that might have been exposed to sunlight. Nevertheless, the possibility that some unintended light exposure took place cannot be completely ruled out.

\subsection{Dose rate determination}

Radionuclide concentrations were measured using highresolution gamma spectrometry, and compared with the results from chemical analyses by ICP-MS (for uranium and thorium concentration) and XRF (for potassium concentration; Fig. 3). Mass concentrations were converted to activity concentrations $\left(\mathrm{Bq} \mathrm{kg}^{-1}\right)$ using the conversion factors presented in Aitken $(1985,1998)$. Given the limited range of concentrations, the agreement is considered acceptable, but since the sample mass used in gamma spectrometry is $\sim 200$ times larger than that used in ICP-MS and XRF, the gamma spectrometer data are considered more likely to be representative. As a result, only the gamma spectrometry data were used in age calculations, but nevertheless the ICP-MS and XRF results serve to confirm that no unexpected gross errors have occurred. The borehole samples were almost certainly water saturated throughout the burial period, and cosmic ray contributions were estimated for the appropriate altitude, latitude, longitude, and burial depth (Prescott and Hutton, 1988, 1994). The saturated water contents were determined by rewetting the core sediments in the laboratory. The water contents of the terrace samples were determined immediately after returning to the laboratory, and the field water contents are assumed to represent the average water content throughout the burial period. 


\section{a}

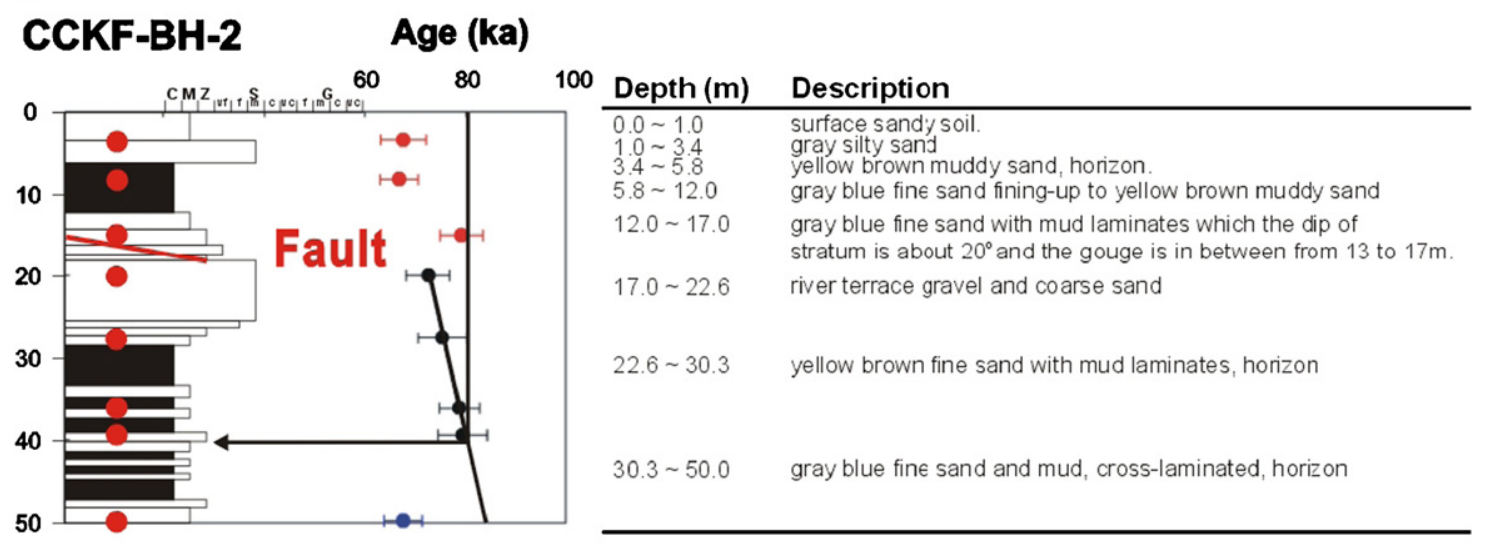

b

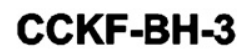

Age (ka)

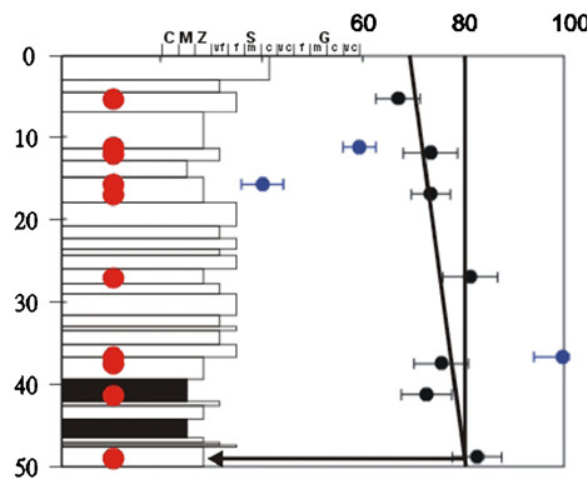

100 Depth (m) Description

\begin{tabular}{ll}
\hline $0.1 \sim 4.2$ & gray blue very fine sand, horizon \\
$4.2 \sim 6.9$ & $\begin{array}{l}\text { yellow brown fine sand with very fine sand laminates } \\
\text { silt with laminated clay }\end{array}$ \\
$6.9 \sim 11.3$ & very fine sand / silt with laminated clay \\
$11.3 \sim 20.0$ & gray blue fin€ sand \\
$20.0 \sim 26.0$ & \\
& fine sand \\
$26.0 \sim 44.4$ & $\begin{array}{l}\text { mud with silt } \\
\text { grasish white to yellow brown silt }\end{array}$ \\
$44.4 \sim 46.5$ & gray black very fine sand \\
$46.5 \sim 47.8$ &
\end{tabular}

Fig. 2. The stratigraphic descriptions of the two boreholes (Liu et al., 2003) together with the sampling positions to the left (red solid circles) and OSL ages to the right. (a) The OSL ages from the hanging wall in CCKF-BH-2 are shown in red solid circles, and those from the footwall are in black solid circles. The accumulation rate of the lower section is $\sim 2.7 \mathrm{~m} \mathrm{ka}^{-1}$. (b) The accumulation rate in CCKF-BH-3 is $\sim 4.5 \mathrm{~m} \mathrm{ka}^{-1}$ (black solid circles). Anomalous ages (blue solid circles) are also shown to the right and discussed in the text.

Dose rates in the range $2.01-3.48 \mathrm{~Gy} \mathrm{ka}^{-1}$ were obtained and are listed in Table 1.

\section{Luminescence characteristics}

The single-aliquot regenerative-dose (SAR; Murray and Wintle, 2000, 2003; Wintle and Murray, 2006) protocol has been applied previously to borehole deposits on the southwestern coastal plain in Taiwan (Chen et al., 2003b), and it is known that quartz from these sediments is sensitive and dominated by the fast component (e.g. decay curve in Fig. 6). Quartz grains $(90-150 \mu \mathrm{m})$ were cleaned using $\mathrm{HCl}, \mathrm{H}_{2} \mathrm{O}_{2}$, and $\mathrm{HF}$ in the standard way, and checked for feldspar contamination using IR stimulation. All measurements were undertaken using a Risø TL/OSL-DA-15 reader with blue $(470 \mathrm{~nm})$ light stimulation, and luminescence detection was through $7 \mathrm{~mm}$ of U-340 filter (Bøtter-Jensen et al., 2000).

\subsection{Preheat plateaus}

To determine the appropriate thermal treatments in the SAR protocol, a preheat plateau was measured for sample 030715-02 (Fig. 4). The $D_{\text {e }}$ appears to be constant in the temperature interval $220-280^{\circ} \mathrm{C}$. The relevant recycling ratios $\left(R_{5} / R_{1}\right)$ were all close to unity $(1.026 \pm 0.008)$, and recuperation was small compared to the natural signal $\left(R_{4} / N<3 \%\right)$. All subsequent measurements reported employed a $220^{\circ} \mathrm{C}$ preheat for $10 \mathrm{~s}$.

\subsection{Dose recovery tests}

To test the ability of our protocol to measure a known dose accurately using previously unheated samples, 12 aliquots from each of two samples (030715-01, 030715-02) were first bleached with blue light at room temperature before being given a known beta dose slightly higher than the measured $D_{\mathrm{e}}$ of Table 1. Afterwards, a routine SAR sequence was used to measure the $D_{\mathrm{e}}$ (Fig. 5). The average ratio of measured to given doses was $0.99 \pm 0.02$ (030715$01, n=12)$ and $0.94 \pm 0.02(030715-02, n=12)$. The SAR protocol applied to the quartz from this region allows reliable assessment of known laboratory doses.

\subsection{Growth curve shape}

When trying to date old samples in a moderately high dose rate environment $\left(\sim 2.5 \mathrm{~Gy} \mathrm{ka}^{-1}\right)$, it is important to 


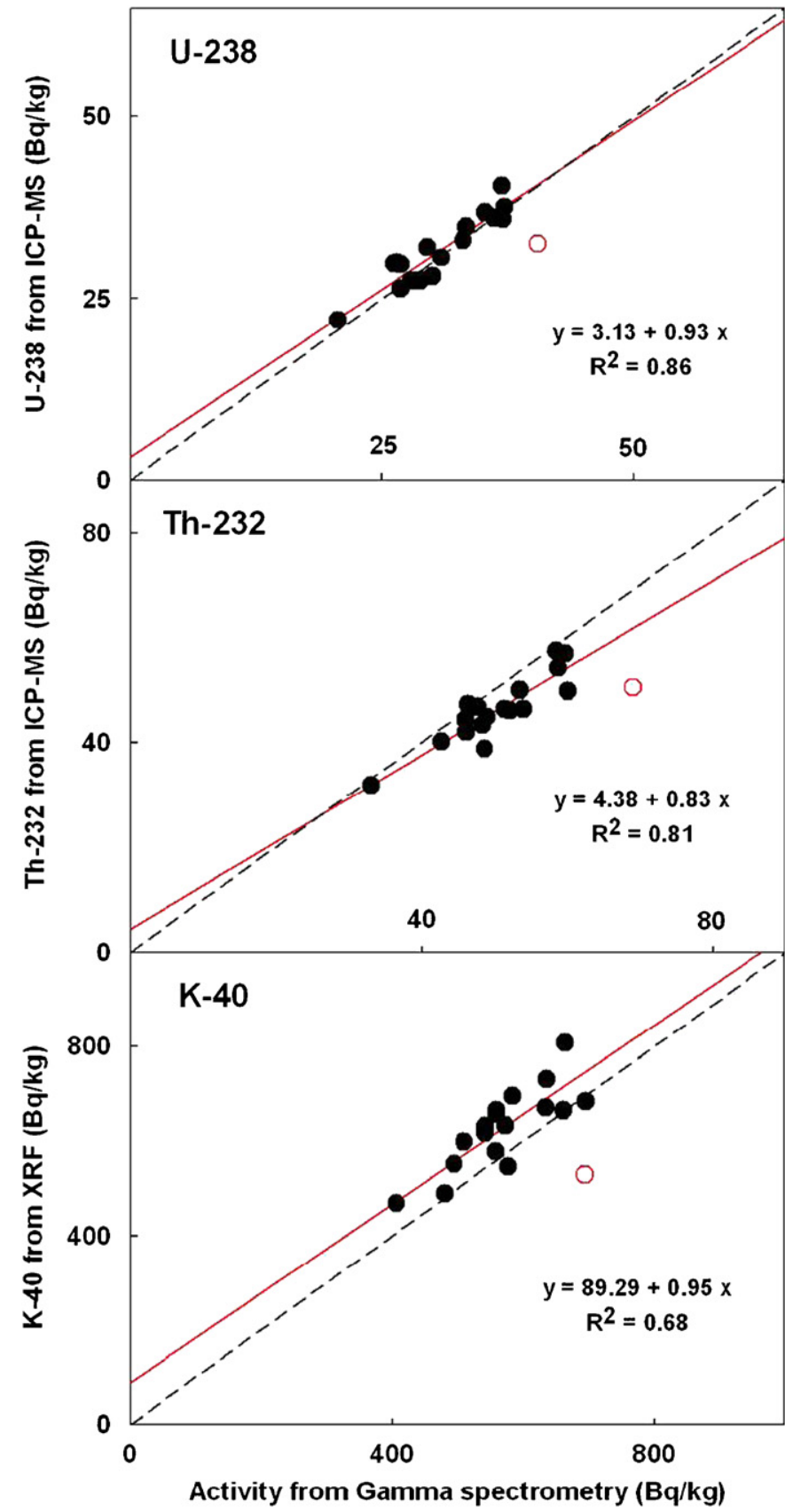

Fig. 3. Comparison of the different radionuclide activities derived from gamma spectrometry and chemical analyses (ICP-MS \& XRF) for 18 samples. One sample (CCKF-BH-3-10) shows clear underestimated radionuclide activities from chemical analyses (open circles).

investigate the upper limit to the dose that can be measured before saturation of the luminescence signal. Two singlealiquot growth curves fitted with two saturating exponentials from two samples serve to illustrate the typical behaviour of these samples (Fig. 6). For sample 03071501 , the slope becomes linear above $\sim 500$ Gy but continues to rise slowly $\left(D_{0} \sim 125 \mathrm{~Gy}\right.$ and $\left.D_{1} \sim 1111 \mathrm{~Gy}\right)$, whereas sample 030715-02 saturates at $\sim 500 \mathrm{~Gy}\left(D_{0} \sim 233 \mathrm{~Gy}\right.$ and $\left.D_{1} \sim 21 \mathrm{~Gy}\right)$. Therefore, both aliquots could be used to determine equivalent doses well above the actual values observed. The recycling points at the lowest and highest doses show variation of $<10 \%$, and recuperation tests that were placed in between every three different regenerated doses give a signal of $<7 \%$ of the natural signal. The decay curves are dominated by the fast component and the signal intensity drops by $\sim 50 \%$ within $1 \mathrm{~s}$ of stimulation.

Since the growth curve shape seems to allow dose measurement up to several hundred Gy, equivalent doses were measured for all samples using the SAR protocol. These data were used to derive 20 luminescence ages, and all the results are summarised in Table 1 .

\subsection{Single-aliquot regeneration and added (SARA) OSL method}

Without discussing the ages in Table 1 in detail, it is clear there is very little increase in age with depth in either of the two cores, and the values of $D_{\mathrm{e}}$ are all high, some well over $200 \mathrm{~Gy}$. Although the SAR characteristics seem to allow dating in this range, one must always be cautious when measuring large doses with quartz, and the lack of increase in age with depth suggests at least the possibility of saturation effects. Accordingly, the single-aliquot regeneration and added dose (SARA) approach (Mejdahl and Bøtter-Jensen, 1997) was also employed, to check for the existence of any unidentified sensitivity change during the measurement of the natural signal. Thirty aliquots of 030715-02 were divided into five groups and a different beta dose $(0,80,160,240,320 \mathrm{~Gy})$ was added to each group. The SAR protocol was then used to measure the total dose recorded by each aliquot (the first group gives a natural dose of $290 \pm 20 \mathrm{~Gy}$ ). When the measured total dose is plotted against the added laboratory dose, the resulting correlation should be linear (Murray, 1996) and the intercept on the added dose axis should give a $D_{\mathrm{e}}$, independent of any sensitivity changes occurring during the first OSL stimulation (Fig. 7). If the slope of this line is unity, then there has been no such change in sensitivity, and the SAR $D_{\text {e }}$ (i.e. the dose recovered by the routine SAR sequence) should be identical to the SARA $D_{\text {e }}$ (i.e. the intercept on the dose axis). In Fig. 7, the ratio of the SAR $D_{\mathrm{e}}(290 \pm 20 \mathrm{~Gy})$ to the SARA $D_{\mathrm{e}}(301 \pm 36 \mathrm{~Gy})$ is 0.96 . Any sensitivity changes thus are considered as minimal, and have resulted in errors in the SAR $D_{\mathrm{e}}$ of $\sim 4 \%$. It is interesting to note that the SAR growth curve of 030715-02 (Fig. 6) suggests that an added dose of $300 \mathrm{~Gy}$ (as used in SARA) should bring the OSL signal close to saturation; nevertheless, the SARA and SAR results are in good agreement.

\subsection{Multiple-aliquot method}

To further check that our samples are not saturated, the traditional multiple-aliquot additive and regenerative dose technique was applied to the oldest sample (030715-02) based on the "Australian slide method" described by Prescott et al. (1993). An additive dose growth curve was 
Table 1

OSL ages and the total dose rates from gamma spectrometry

\begin{tabular}{|c|c|c|c|c|c|c|}
\hline Code & $\begin{array}{l}\text { Depth or } \\
\text { elevation }(\mathrm{m})\end{array}$ & $\begin{array}{l}\text { Equivalent dose }{ }^{a} \\
\text { (Gy) }\end{array}$ & $n$ & $\begin{array}{l}\text { Dose rate } \\
\left(\mathrm{Gy} \mathrm{ka}^{-1}\right)\end{array}$ & $\begin{array}{l}\text { Water content } \mathrm{c}^{\mathrm{c}} \\
(\%)\end{array}$ & Age (ka) \\
\hline CCKF-BH-2-1 & 3.4 & $211 \pm 11$ & 30 & 3.12 & 24 & $68 \pm 5$ \\
\hline CCKF-BH-2-2 & 8.2 & $196 \pm 7$ & 30 & 2.94 & 24 & $67 \pm 4$ \\
\hline CCKF-BH-2-3 & 15.0 & $208 \pm 6$ & 30 & 2.63 & 19 & $79 \pm 4$ \\
\hline CCKF-BH-2-4 & 20.0 & $188 \pm 7$ & 30 & 2.59 & 22 & $72 \pm 4$ \\
\hline CCKF-BH-2-7 & 27.6 & $221 \pm 10$ & 30 & 2.94 & 23 & $75 \pm 5$ \\
\hline CCKF-BH-2-5 & 36.1 & $208 \pm 5$ & 30 & 2.65 & 32 & $79 \pm 4$ \\
\hline CCKF-BH-2-8 & 39.4 & $197 \pm 8$ & 30 & 2.48 & 25 & $79 \pm 5$ \\
\hline CCKF-BH-2-6 & 49.8 & $167 \pm 5$ & 30 & 2.46 & 22 & $68 \pm 4$ \\
\hline CCKF-BH-3-1 & 5.1 & $135 \pm 6$ & 27 & 2.01 & 21 & $67 \pm 4$ \\
\hline CCKF-BH-3-2 & 11.2 & $155 \pm 5$ & 27 & 2.61 & 26 & $59 \pm 3$ \\
\hline CCKF-BH-3-7 & 11.9 & $175 \pm 10$ & 30 & 2.39 & 19 & $73 \pm 5$ \\
\hline CCKF-BH-3-3 & 15.7 & $149 \pm 9$ & 24 & 3.18 & 24 & $45 \pm 3$ \\
\hline CCKF-BH-3-8 & 16.9 & $192 \pm 5$ & 30 & 2.62 & 21 & $73 \pm 4$ \\
\hline CCKF-BH-3-4 & 27.0 & $211 \pm 10$ & 27 & 2.59 & 20 & $81 \pm 5$ \\
\hline CCKF-BH-3-9 & 36.7 & $273 \pm 11$ & 30 & 2.73 & 23 & $100 \pm 6$ \\
\hline CCKF-BH-3-5 & 37.5 & $231 \pm 12$ & 27 & 3.06 & 17 & $75 \pm 5$ \\
\hline CCKF-BH-3-10 & 41.3 & $253 \pm 13$ & 30 & 3.48 & 20 & $73 \pm 5$ \\
\hline CCKF-BH-3-6 & 48.9 & $214 \pm 8$ & 27 & 2.59 & 24 & $83 \pm 5$ \\
\hline 030715-01 & 420 (m.a.s.1.) & $209 \pm 19$ & 12 & 2.61 & 8 & $80 \pm 7$ \\
\hline 030715-02 & 617 (m.a.s.l.) & $273 \pm 15$ & 12 & 2.61 & 9 & $105 \pm 8$ \\
\hline
\end{tabular}

a Standard errors calculated using results from ' $n$ ' aliquots.

${ }^{\mathrm{b}}$ Based on gamma spectrometry activity results, converted to dose rates using the data of Olley et al. (1996), and cosmic ray contribution based on Prescott and Hutton (1988, 1994).

${ }^{\mathrm{c}}$ Water contents are measured after taking samples back to the laboratory and are assumed to be saturated since the depths for all samples are below the groundwater table. The last two dissected fan samples are exceptions, which are measured immediately after taking samples.

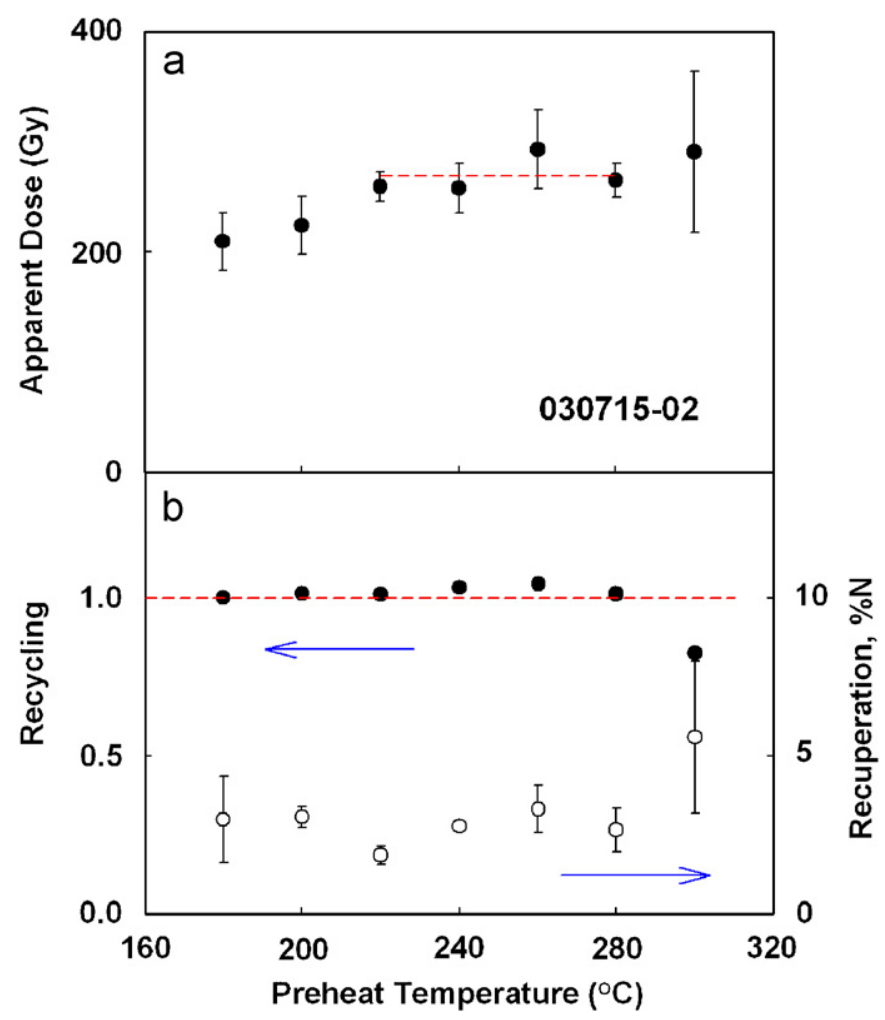

Fig. 4. (a) Preheat plateau and (b) recycling ratios and recuperation, for representative sample $030715-02$. Preheats from 220 to $280^{\circ} \mathrm{C}$ gave a constant $D_{\mathrm{e}}$ with three aliquots measured at each temperature; the cutheat temperature was fixed at $160^{\circ} \mathrm{C}$. constructed using 72 aliquots, with added doses of up to $\sim 1700 \mathrm{~Gy}$. This approach is intended to avoid any change in characteristics resulting from repeated dosing and heating and any dose-quenching effects. A further 48 aliquots were used to regenerate the growth curve by bleaching with blue light at room temperature in the TL/OSL reader, and then adding laboratory doses. After additive or regenerated doses, a preheat of $220^{\circ} \mathrm{C}$ was given and a short shine $(0.1 \mathrm{~s})$ at room temperature and full signal depletion $(40 \mathrm{~s})$ followed. The response to a test dose (after preheat and stimulation) was used to normalise the response between the different aliquots. In Fig. 8, the added dose laboratory growth curve (solid symbols) is seen to saturate at an added dose of $\sim 500 \mathrm{~Gy}$. The regenerated dose laboratory growth curve (open symbols) has a curvature consistent with the additive dose growth curve (the data can be represented by the sum of two exponentially saturating growth curves, with $D_{0}=85$ and $D_{1}=411 \mathrm{~Gy}$ ). Both curves were fitted together by shifting along the dose axis. Taken together, these data suggest an average equivalent dose of $221 \pm 7$ Gy (Fig. 8). This estimate of $D_{\mathrm{e}}$ is certainly not larger than the SAR result of $273 \pm 15$ Gy (see Table 1).

In summary, a comparison of three different methods for determining $D_{\mathrm{e}}$ has not provided any evidence that the SAR method underestimates the burial dose. It may be that the added dose method gives a slightly lower result, but this is presumed to arise most likely from the additional 


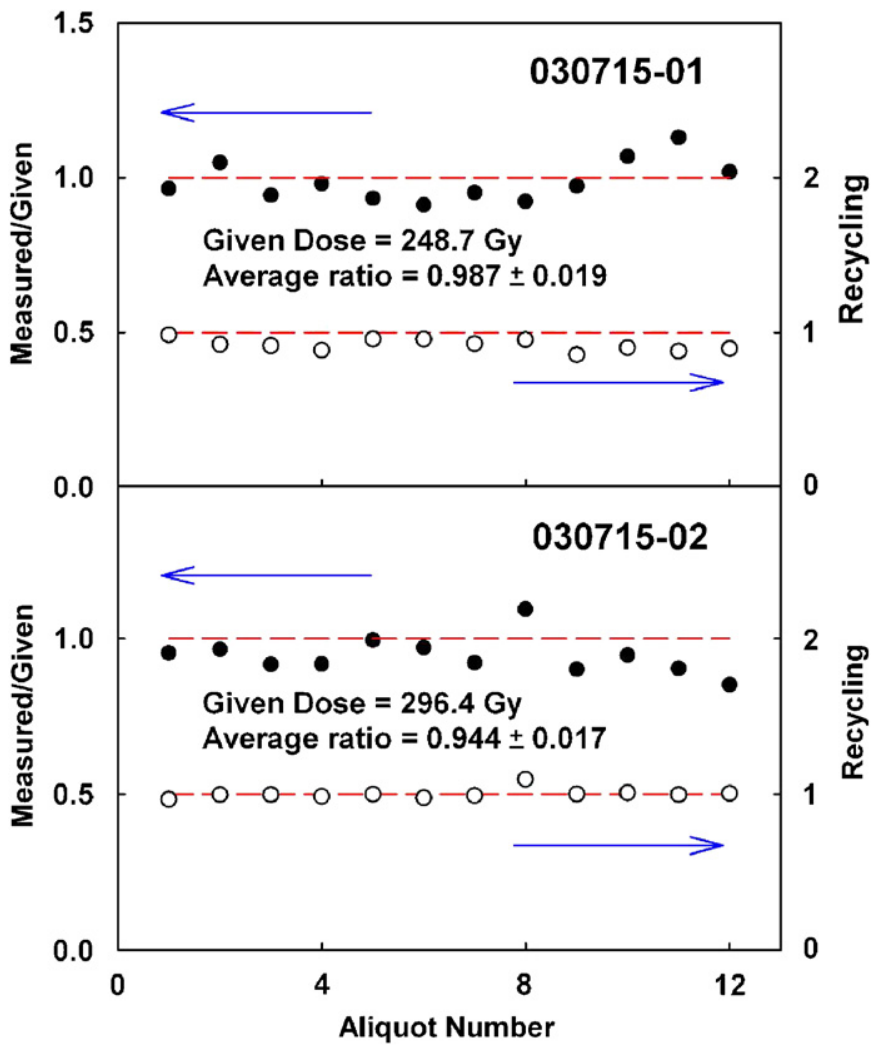

Fig. 5. Dose recovery tests for samples 030715-01 and 030715-02. Twelve aliquots of each sample were measured using a $220^{\circ} \mathrm{C}$ preheat and $160{ }^{\circ} \mathrm{C}$ cut-heat temperature. The given dose was selected to be close to the equivalent dose. The ratios of measured to given dose are shown as solid circles, and the recycling ratios $\left(R_{5} / R_{1}\right)$ of each aliquot are shown as open circles.

uncertainties inherent in the method (e.g. in matching the additive and regenerative curves, especially for data approaching saturation).

\section{Discussion}

\subsection{Borehole stratigraphy and luminescence ages}

As discussed above a shear zone at a depth of $13-17 \mathrm{~m}$ has been found in CCKF-BH-2 (Liu et al., 2003; Figs. 1 and 2a). The gravels lying directly below the fault zone at $\sim 20 \mathrm{~m}$ are identified as the fluvial bed correlated with the terrace observed at the Tahukou outcrop nearby (Chen et al., 2003a). In other words, this borehole records two sections superimposed by more recent CCKF action. As a result, age duplication may exist but the establishment of any correlation is impossible without the establishment of the chronological framework. Since CCKF-BH-3 is located directly to the west of the CCKF, it can be used to establish a chronological framework for the deposition of the sediments making up the footwall.

The OSL age at the bottom of CCKF-BH-2 appears to be underestimated compared to the ages above. Since there is no apparent shear zone between $39.4 \mathrm{~m}(79 \pm 5 \mathrm{ka})$ and

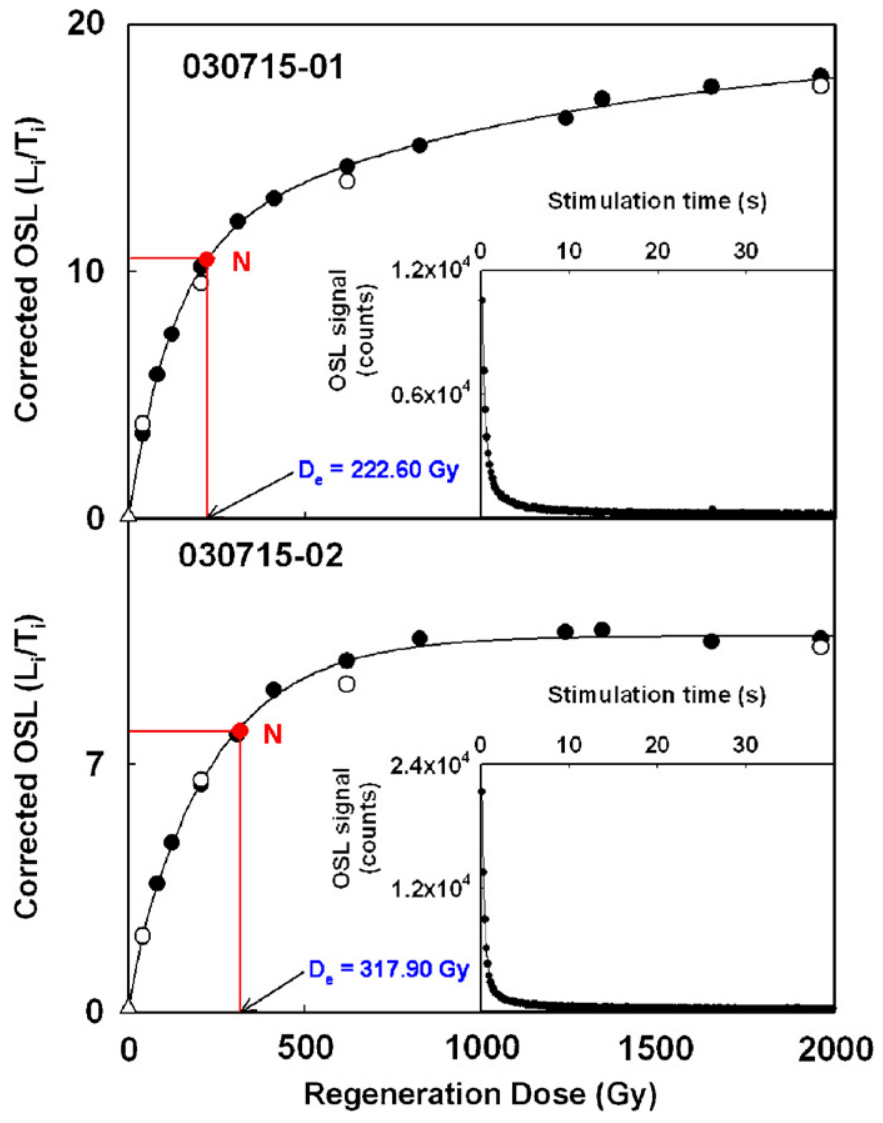

Fig. 6. Growth curves for samples 030715-01 and 030715-02. The SAR protocol was applied using 12 different regenerative doses. Three of these were repeated (open circles) and zero regenerative doses show recuperation close to zero (open triangles). The test doses were 8.3 and $12.4 \mathrm{~Gy}$, respectively. Typical OSL curves (shown inset) are dominated by the fast component.

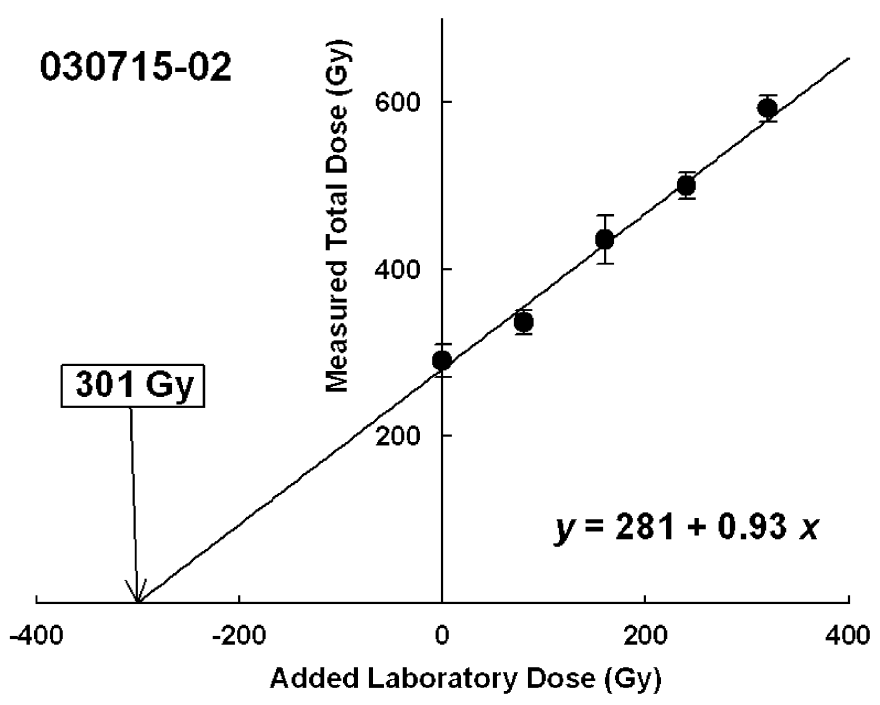

Fig. 7. SARA measurement for sample 030715-02. Different added doses, from 0 to $320 \mathrm{~Gy}$, were given to five groups each of six natural aliquots; the correlation coefficient of added vs. measured doses is 0.992 , indicating no sensitivity change in the natural. 


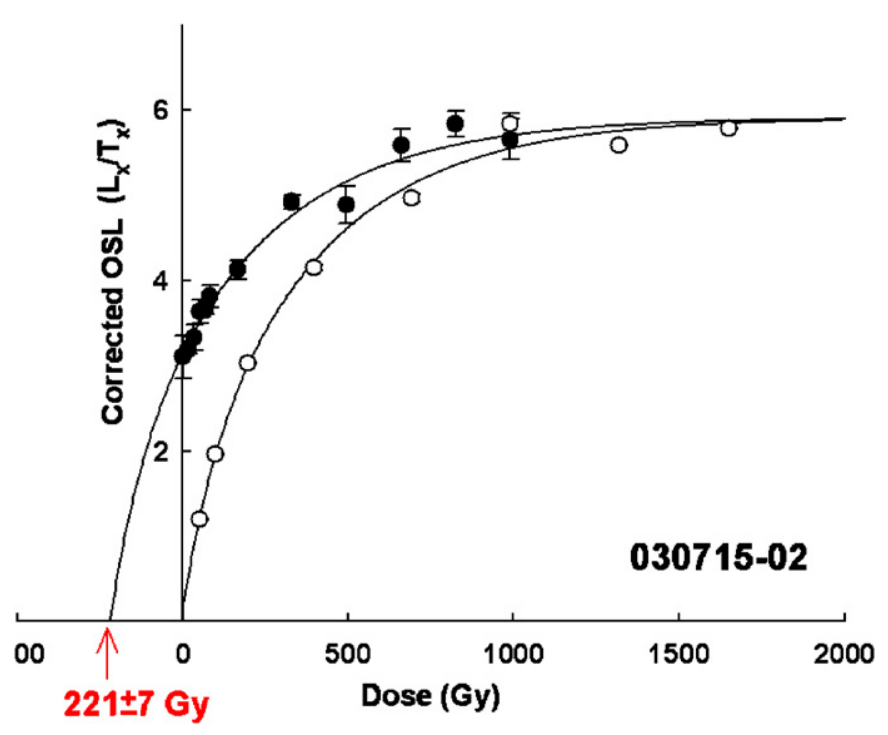

Fig. 8. Multiple-aliquot measurement of sample 030715-02. The aliquots represented by open circles were first bleached with blue light, and then irradiated to regenerate a laboratory growth curve. The aliquots represented by solid circles received added doses on top of the natural. The same regression parameters were used to fit both data sets, and the correlation coefficient of both pairs of dose and corrected $\operatorname{OSL}\left(\mathrm{L}_{x} / \mathrm{T}_{x}\right)$ is 0.998 . The resulting $D_{\mathrm{e}}$ is $221 \pm 7 \mathrm{~Gy}$.

$49.8 \mathrm{~m}(68 \pm 4 \mathrm{ka})$, there is no stratigraphic reason for this inversion; nor are there any unusual luminescence characteristics to account for this anomalous behaviour. However, as this sample was taken only $\sim 20 \mathrm{~cm}$ away from the bottom of the section, it is very possible that there had been undetected damages, such as minor cracking, that had occurred during unloading and splitting immediately after coring. This could have easily given rise to unexpected light exposure some time before sampling for luminescence studies.

Although the $50 \mathrm{~m}$ sedimentary sequence appears to have been deposited within $10 \mathrm{ka}$, the chronological difference in CCKF-BH-2 caused by the faulting is obvious. The fault plane at $17 \mathrm{~m}$ (Liu et al., 2003) can be used as a divide: the lower section is from $72 \mathrm{ka}$ older downwards; the upper section is from $79 \mathrm{ka}$ younger upwards. The average age of the uppermost part of this borehole is $68 \mathrm{ka}$, and the accumulation rate of the lower section is $\sim 2.7 \mathrm{~m} \mathrm{ka}^{-1}$.

In CCKF-BH-3, the ages at $11.2 \mathrm{~m}(59 \pm 3 \mathrm{ka}), 15.7 \mathrm{~m}$ $(45 \pm 3 \mathrm{ka})$, and $36.7 \mathrm{~m}(100 \pm 6 \mathrm{ka})$ are also stratigraphically inverted, and so the adjacent samples at $11.9 \mathrm{~m}$ $(73 \pm 5 \mathrm{ka}), 16.9 \mathrm{~m}(73 \pm 4 \mathrm{ka})$, and $37.5 \mathrm{~m}(75 \pm 5 \mathrm{ka})$ were sampled subsequently to test these anomalous ages. These repeated ages fit well with the overall pattern, suggesting that the earlier results are unreliable. The $D_{\mathrm{e}}$ distributions of both the original and duplicated samples do not show any evidence of contamination with bleached grains (always of concern with these samples because of prior storage condition; see Section 2.2). It is not known whether the anomalous ages arise because of errors in the apparent dose or in assessing saturated water content. Nevertheless, the overall chronological trends are reliable, and these data except those anomalous ones $(11.2,15.7$, and $36.7 \mathrm{~m}$ ) can be used to compute an accumulation rate for CCKF-BH-3 of $\sim 4.5 \mathrm{~m} \mathrm{ka}^{-1}$.

\subsection{Behaviour of the $C C K F$}

Based on the $72 \pm 4 \mathrm{ka}$ age of the youngest sediments truncated by the faulting, the latest fault movement must occur thereafter (CCKF-BH-2-4; Fig. 2a). Since there are late Pleistocene sedimentary sequences on both sides of the fault, the regional ground displacement can be derived by the reconstruction of the paleo-ground surface. Furthermore the slip rate along the subsurface fault plane can be estimated by examining the current fault geometry. In the hanging wall, the sediments represented by sample 030715 01 were identified as an abandoned alluvial fan, developed in association with the eastern mountain rise. This fan was lifted up by movement of the TCSF (Fig. 1) and abandoned subsequently because of the action of the CCKF. Although the fan surface has been dissected, it is still recognizable by tracing the relic fan surfaces (Fig. 9a). The present day slope of this abandoned fan is $4.0^{\circ}$, which is much steeper than the slope of the modern active fan, namely $1.6^{\circ}$. This suggests that the regional total slip along the subsurface CCKF may transform the slip into hanging wall folding near the surface. If we take the $1.6^{\circ}$ as the slope at the time of deposition, the averaged tilt rate over the past $80 \mathrm{ka}$ is $\sim 42 \mathrm{~m} \mathrm{~km}^{-1}$ to the west (Fig. 9b). Computation of the near-surface fault slip uses the published fault geometry suggested by field surveying (dipping $25^{\circ}$ to the east; Chen et al., 2003a) and the chronological data presented in this study. Since the abandoned fan surface in the hanging wall formed at around $80 \mathrm{ka}(030715-01)$, the $80 \mathrm{ka}$ sediments in the footwall must be identified before computation of the longterm slip rate. The two regression lines of OSL age against depth in the footwall from boreholes CCKF-BH-2 and CCKF-BH-3 are shown in Fig. 2. The $80 \mathrm{ka}$ surface appears to lie at depths of $\sim 40.5$ and $\sim 49.1 \mathrm{~m}$, respectively. An average value of $44.8 \mathrm{~m}$ is used as the depth of the $80 \mathrm{ka}$ surface in the footwall. Based on the current slopes of the abandoned fan surface in the hanging wall $\left(4.0^{\circ}\right)$ and modern flood plain in the footwall $\left(1.6^{\circ}\right)$, a profile of tie lines has been constructed at $80 \mathrm{ka}$ and a fault plane to show the total slip (Fig. 9c). Along the fault plane, correcting for the offset between the $80 \mathrm{ka}$ surface on both sides yields a total slip of $117 \mathrm{~m}$. Assuming a negligible strike slip (Lin et al., 2007), the long-term average slip rate of the CCKF is $\sim 1.5 \mathrm{~m} \mathrm{ka}^{-1}$ along its near-surface fault plane. This value is consistent with a previous study based on radiocarbon ages of river terraces, which derived a minimum slip rate of $0.55 \mathrm{~m} \mathrm{ka}^{-1}$ (Lin et al., 2007). As discussed earlier, the CCKF also developed a hanging wall tilt to the west at around $42 \mathrm{~m} \mathrm{~km}^{-1}$, indicating that the deeper part of the fault may be slipping faster, but some of this slip is transformed into a hanging wall fold. To develop 


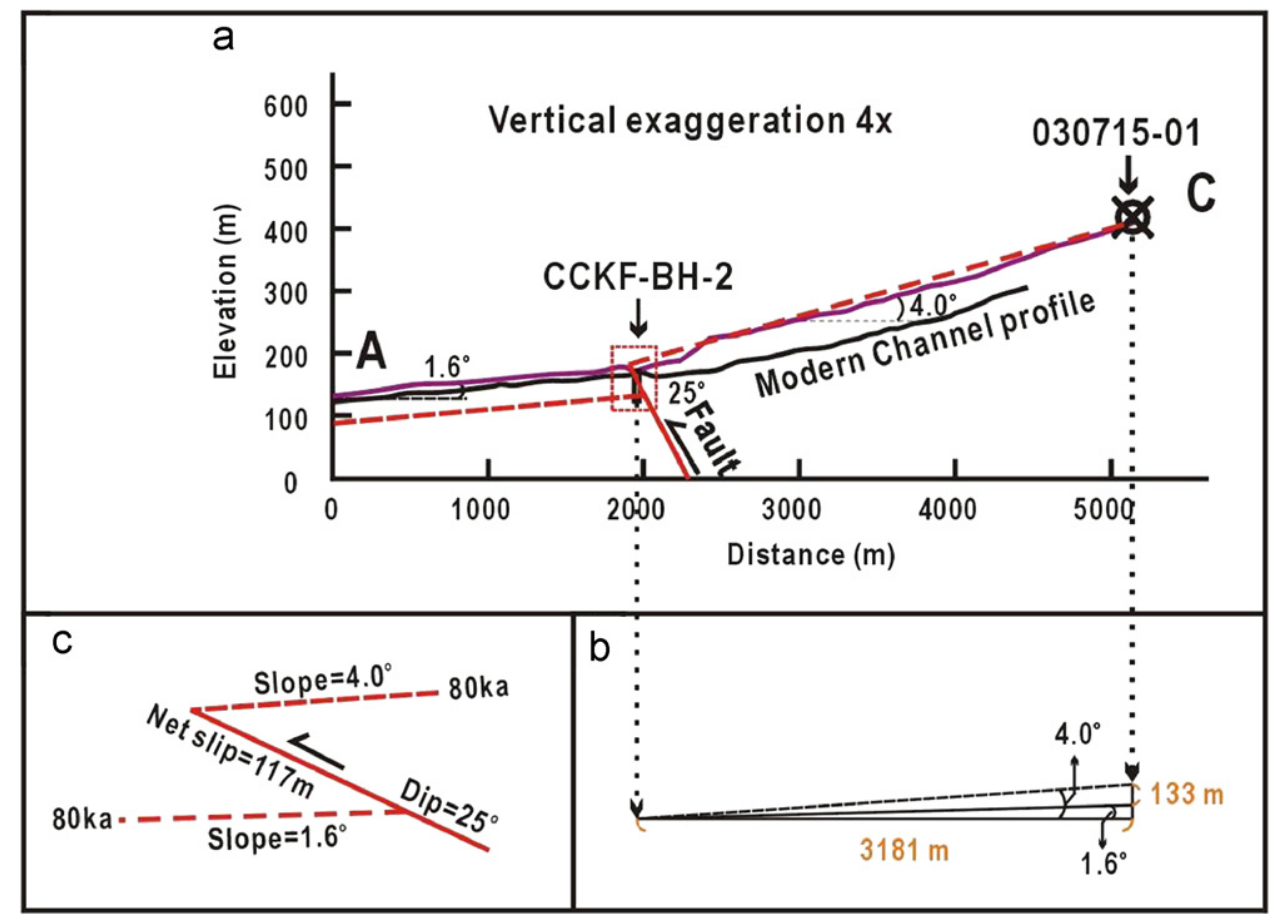

Fig. 9. Schematic profile across CCKF. (a) The traces of relic fan surface and modern channel are shown together with the location of sample 030715-01. The results from CCKF-BH-2 are used to represent the behaviour of the footwall. The identification of the 80 ka synchronous surface in the hanging wall and footwall is discussed in the text. (b) The different slopes of the abandoned fan surface in the hanging wall and modern fluvial channel in the footwall are compared to calculate the tilting rate over the past $80 \mathrm{ka}$. (c) An enlarged plot of the square area is used to explain the calculation of the long-term slip rate of CCKF.

a more detailed understanding of the kinematics of this process, further study is required to provide additional constraints on the subsurface fault geometry.

\section{Conclusion}

All age results from the dissected fans and the boreholes deposits are beyond the radiocarbon age limit, consistent with the results of the woody samples taken from the outcrops (Fig. 1; Hsu, 2003). Based on the slip distance $(117 \mathrm{~m})$ inferred from correlation of the $80 \mathrm{ka}$ surface across the hanging wall and footwall, a long-term average slip rate of $1.5 \mathrm{~m} \mathrm{ka}^{-1}$ is derived for the near-surface section of CCKF in this area. The last fault action must have occurred more recently than $72 \pm 4 \mathrm{ka}$, based on hanging wall age results from the top of the core. This chronology helps in the interpretation of the behaviour of CCKF, but further chronological control and information on subsurface fault geometry are required to better understand the recent kinematic behaviour.

\section{Acknowledgments}

The authors thank for two anonymous reviewers for their constructive comments and two editors, G.A.T. Duller and S. Tsukamoto, for final English checked. We also express our appreciation to Prof. S.L. Chung for supporting us with ICP-MS analyses. This study is financially supported by Central Geological Survey and National Science Council, ROC, under Grant numbers of NSC94-2119-M-002-002 and NSC93-2119-M-002-026.

\section{References}

Aitken, M.J., 1985. Thermoluminescence Dating. Academic Press, London.

Aitken, M.J., 1998. An Introduction to Optical Dating: The Dating of Quaternary Sediments by the use of Photon-Stimulated Luminescence. Oxford University Press, Oxford.

Angelier, J., 1986. Preface. Geodynamics of Eurasia-Philippine sea plate boundary. Tectonophysics 125 , IX-X.

Bøtter-Jensen, L., Bulur, E., Duller, G.A.T., Murray, A.S., 2000. Advances in luminescence instrument systems. Radiation Measurements $32,523-528$.

Chapple, W.M., 1978. Mechanics of thin-skinned fold-and-thrust belts. Geological Society of America Bulletin 89, 1189-1198.

Chen, W.S., Yang, C.C., Shih, R.C., Yang, H.C., Yen, Y.C., Chen, Y.G., Chang, H.C., Lin, W.S., Lee, Y.H., Shih, T.S., Lu, S.T., 2003a. Structural characteristics of the Chiuchiungkeng fault. Special Publication of the Central Geological Survey 14, 123-139 (in Chinese with English abstract).

Chen, Y.W., Chen, Y.G., Murray, A.S., Liu, T.K., Lai, T.C., 2003 b. Luminescence dating of neotectonic activity on the southwestern coastal plain, Taiwan. Quaternary Science Reviews 22, 1223-1229.

Chi, W.R., Shaw, C.L., Huang, S.T., Liu, C.H., Wang, W.H., Chuang, K.C., Lu, D.L., Chou, T.F., Wu, J.C., 1998. Petroleus geology and hydrocarbon accumulation of the Chianan coastal plain - the Pachangchi sandstone and the Cretaceous sequence in the Peikang basement high. Annual report, Petroleum Geology of Taiwan, 5lpp. (in Chinese with English abstract). 
Deffontaines, B., Lacombe, O., Angelier, J., Chu, H.T., Mouthereau, F., Lee, C.T., Deramond, J., Lee, J.F., Yu, M.S., Liew, P.M., 1997. Quaternary transfer faulting in the Taiwan Foothills: evidence from a multisource approach. Tectonophysics 274, 61-82.

Ho, C.S., 1986. A synthesis of the geologic evolution of Taiwan. Tectonophysics 125, 1-6.

Hsu, C.Y., 2003. The Study of Chiuhsiumgken-fault. MS Thesis, National Cheng Kung University, Tainan, 90pp. (in Chinese).

Hung, J.H., Wiltschko, D.V., Lin, H.C., Hickman, J.B., Fang, P., Bock, Y., 1999. Structure and motion of the southwestern Taiwan fold and thrust belt. Terrestrial, Atmospheric and Oceanic Sciences 10, 543-568.

Lin, C.W., Hsu, C.Y., Yu, T.D., 2007. The Chiuhsiungken fault: a candidate to trigger a hazardous earthquake in western Taiwan. Journal of Asian Earth Science 30, 390-402.

Liu, Y.C., Lin, C.W., Lin, Y.H., Lee, M.S., 2003. The drilling report of "Earthquake Geologic Investigation and Data Bank Compilation on Active Faults in Taiwan”. Central Geological Survey (in Chinese).

Lu, C.Y., Jeng, F.S., Chang, K.J., Jian, W.T., 1998. Impact of basement high on the structure and kinematics of the western Taiwan thrust wedge: insights from sandbox models. Terrestrial, Atmospheric and Oceanic Sciences 9, 533-550.

Mejdahl, V., Bøtter-Jensen, L., 1997. Experience with the SARA OSL method. Radiation Measurements 27, 291-294.

Mouthereau, F., Lacombe, O., Deffontaines, B., Angelier, J., Brusset, S., 2001. Deformation history of the southwestern Taiwan foreland thrust belt: insights from tectono-sedimentary analyses and balanced crosssections. Tectonophysics 333, 293-322.

Murray, A.S., 1996. Developments in optically stimulated luminescence and photo-transferred thermoluminescence dating of young sediments: application to a 2000-year sequence of flood deposits. Geochimica et Cosmochimica Acta 60, 565-576.

Murray, A.S., Wintle, A.G., 2000. Luminescence dating of quartz using an improved single-aliquot regenerative-dose protocol. Radiation Measurements 32, 57-73.
Murray, A.S., Wintle, A.G., 2003. The single aliquot regenerative dose protocol: potential for improvements in reliability. Radiation Measurements 37, 377-381.

Olley, J.M., Murray, A.S., Robert, R.G., 1996. The effects of disequilibria in the uranium and thorium decay chain on burial dose rates in fluvial sediments. Quaternary Science Reviews (Quaternary Geochronology) $15,751-760$.

Prescott, J.R., Hutton, J.T., 1988. Cosmic ray and gamma ray dosimetry for TL and ESR. Nuclear Tracks Radiation Measurements 14, 223-227.

Prescott, J.R., Hutton, J.T., 1994. Cosmic ray contribution to dose rates for luminescence and ESR dating: large depths and long-term time variations. Radiation Measurements 23, 497-500.

Prescott, J.R., Huntley, D.J., Hutton, J.T., 1993. Estimation of equivalent dose in thermoluminescence dating - the Australian slide method. Ancient Thermoluminescence 11, 1-5.

Shih, R.C., Chen, P.H., Lu, M.T., Chen, W.S., 2002. Final report of Geophysical Prospecting of Active Faults. Central Geological Survey, Taiwan, 166pp. (in Chinese)

Suppe, J., Namson, J., 1979. Fault-bend origin of frontal folds of the western Taiwan fold-and-thrust belt. Petroleum Geology of Taiwan $16,1-18$.

Teng, L.S., 1990. Geotectonic evolution of late Cenozoic arc-continent collision in Taiwan. Tectonophysics 183, 57-76.

Wang, C.Y., Kuo, H.Y., Wu, M.S., Oung, T.W., 2005. Confirming the Chiuchiungkeng fault by the seismic reflection method. Special Publication of the Central Geological Survey 16, 125-141 (in Chinese with English abstract).

Wintle, A.G., Murray, A.S., 2006. A review of quartz optically stimulated luminescence characteristics and their relevance in single-aliquot regeneration dating protocols. Radiation Measurements 41, 369-391.

Yang, K.M., Huang, S.T., Wu, J.C., Ting, H.H., Mei, W.W., 2006. Review and new insights on foreland tectonics in western Taiwan. International Geology Review 48, 910-941. 